\title{
Efficiency of supercritical fluid extraction for determining 4-nonylphenol in municipal sewage sludge
}

\author{
Jih-Gaw Lin*, Reeha Arunkumar, Chih-Huang Liu \\ Institute of Environmental Engineering, National Chiao Tung University, 75 Po-Ai Street, Hsinchu, Taiwan
}

Received 7 December 1998; received in revised form 5 February 1999; accepted 9 February 1999

\begin{abstract}
When the sewage sludge containing the persistent, lipophilic, metabolite 4-nonylphenol (4-NP) has been disposed of in the environment it's toxic nature can lead to serious health risks to human beings and can also affect plants and aquatic organisms. Supercritical fluid extraction (SFE) is a new and powerful technique for extracting the organic contaminants from the solid phase. The present study was conducted to investigate optimal conditions for the quantitative extraction of 4-NP by SFE and to determine the concentration of 4-NP in municipal sewage sludge. The effect of several parameters such as temperature, pressure, static extraction time, dynamic extraction time, $\mathrm{CO}_{2}$ flow-rate, sample mass and modifier on the extraction were investigated. The optimal conditions for the extraction of the spiked sample were fluid pressure 97 bar, temperature $40^{\circ} \mathrm{C}$, flow-rate $3.0 \mathrm{ml} / \mathrm{min}$, static extraction time $2 \mathrm{~min}$, dynamic extraction time $5 \mathrm{~min}$ and modifier methanol $(0.5 \mathrm{ml})$. Extracts were analyzed by gas chromatography-mass spectrometry. Concentration of 4-NP in the anaerobically degraded sludge of the De-Haw Sewage Treatment Plant in Taiwan was found to be $243.9 \mathrm{mg} / \mathrm{kg}$. The extraction efficiency of the SFE method was compared with the conventional Soxhlet extraction method. The overall recovery of the SFE method was found to be greater and the results indicate that SFE is an efficient method for extracting 4-NP from sewage sludge. (c) 1999 Elsevier Science B.V. All rights reserved.
\end{abstract}

Keywords: Environmental analysis; Sewage sludge; Extraction methods; Nonylphenol; Phenols; Polyethoxylates

\section{Introduction}

Anaerobic biodegradation of the nonionic surfactants nonylphenol polyethoxylates (NPEs) in sewage sludge leads to the formation of higher concentrations of 4-nonylphenol (4-NP) [1]. The persistent contaminant, 4-NP, in the environment has recently been of increasing concern due to its toxic and estrogenic effects. The strong estrogenic nature of

*Corresponding author. Tel.: +886-3-572-2681; fax: +886-3-5725958.

E-mail address: jglin@green.ev.nctu.edu.tw (J.-G. Lin)
4-NP can cause feminization of male fish resulting in a lack of reproductive success, and is also linked to the fertility problems in men and cancer in human beings [2]. Therefore, it is necessary to develop an effective treatment method for sewage sludge containing the environmentally threatening 4-NP before disposal into the environment.

Recently, supercritical fluid extraction (SFE) has been found to be a better alternative to the conventional liquid solvent extraction methods (Soxhlet and sonication) for the extraction of environmental samples. This is due to several advantages such as rapid extraction, low solvent requirement, low cost and 
higher efficiency. The most popular fluid for SFE has been $\mathrm{CO}_{2}$ because of its low critical properties $\left(T_{\mathrm{c}}=\right.$ $32^{\circ} \mathrm{C}, P_{\mathrm{c}}=72 \mathrm{bar}$ ), high purity, low toxicity and cost, chemical inertness, and its ability to solvate a wide range of organic compounds including those having higher molecular mass. However, the limitation of $\mathrm{CO}_{2}$ is that it is unable to extract the polar organic solutes quantitatively from the environmental samples even though the solutes are soluble in supercritical $\mathrm{CO}_{2}$. This shows that the extraction of polar molecules requires an addition of modifiers or cosolvents to the carbon dioxide. The commonly used modifier in SFE is methanol. Recovery of solutes from the spiked samples is necessary for optimizing the SFE conditions in order to achieve quantitative recovery of the target compound. Determining the recovery of solutes from spiked environmental samples is a routine procedure for developing new extraction methods. However the optimal conditions that yield quantitative recoveries of spiked solutes may recover $<10 \%$ of the same solutes from real world samples, because spiked pollutants are not exposed to the same active sites as that of the native pollutants [3].

The purpose of this investigation was to obtain quantitative recovery of 4-NP from real world samples by optimizing the extraction parameters using 4-NP-spiked samples. Several investigations have already been carried out to study the effect of extraction parameters during SFE and to determine organic contaminants including 4-NP and 4-NPEs [4-8]. The present study investigated the effect of several extraction parameters such as pressure, temperature, static extraction time, dynamic extraction time, $\mathrm{CO}_{2}$ flow-rate, sample mass, 4-NP content and modifier on the extraction efficiency. The conventional Soxhlet extraction was also carried as a comparison. The recovery of 4-NP under the optimal conditions was compared with the recovery of other organic pollutants by other researchers using SFE.

\section{Experimental}

\subsection{Materials}

4-NP, pentane and methanol were obtained from Tokyo Chemicals (90\%) (Japan), Fisons (99.4\%)
(UK), and RDH (99.8\%), respectively. The other solvents hexane and dichloromethane used in this study were of gas chromatography (GC)-grade. SFEgrade carbon dioxide was obtained from Air Products (Nepean, Canada).

\subsection{Preparation of 4-NP standard}

The stock solution of 4-NP standard was prepared in pentane. Standard solutions of different concentrations such as 1.406, 2.813, 5.625, 11.25, 22.5 and $45 \mathrm{mg} / \mathrm{l}$ were prepared by diluting the stock solution. Each solution was analyzed using GC-mass spectrometry (MS) (HP 1800A GCD, USA). Quantification of 4-NP was performed using a calibration curve, which was constructed by plotting the abundance of total ion chromatogram peak versus the different concentrations of 4-NP. The method detection limit of 4-NP obtained was $0.88 \mathrm{mg} / \mathrm{l}$.

\subsection{Sample preparation}

Samples were obtained from several sewage/ wastewater treatment plants in Taiwan (Pure Terephthalic Acid manufacturing industry, De-Haw, Min-Shan, President, and Hsin-Chu sewage/wastewater treatment plants). The samples were air-dried, ground and homogenized by passing through a 30mesh sieve. Spiking of 4-NP (100 mg/l) was done on quartz sand and the sludge of Hsin-Chu wastewater treatment plant that treats the waste of cows and pigs. After spiking, the slurry was shaken for $6 \mathrm{~h}$ at $1000 \mathrm{rpm}$ and allowed to stand for $24 \mathrm{~h}$ to evaporate the solvent. The amount of 4-NP found both in the quartz sand and sludge was $90 \mathrm{mg} / \mathrm{kg}$.

\subsection{SFE method}

SFE experiments were performed using a HewlettPackard 7680T supercritical fluid extractor. For 4-NP spiked quartz sand studies, a stainless steel HP extraction thimble $(7 \mathrm{ml}, 90 \times 10 \mathrm{~mm}$ I.D.) was plugged first with glass wool. Then it was filled with $0.5 \mathrm{~g}$ of quartz sand and $1 \mathrm{~g}$ of $\mathrm{Na}_{2} \mathrm{SO}_{4}$ and again plugged with glass wool. With spiked anaerobic sludge and raw sludge containing 4-NP, the extraction thimble was packed as before with 0.2 or 0.5 $\mathrm{g}$ of sludge sample. $\mathrm{Na}_{2} \mathrm{SO}_{4}$ and methanol $(0.5 \mathrm{ml})$ 
were added to the thimble at different sites to study their effects on the extraction. The supercritical carbon dioxide extractions were carried out in triplicate with the spiked as well as raw sludge. The effect of parameters such as pressure, temperature, flow-rate, static extraction time, dynamic extraction time, modifier and trap type are often investigated. In our study, the extractions were carried out for different ranges of pressure (77-164 bar), temperature $\left(40-100^{\circ} \mathrm{C}\right), \mathrm{CO}_{2}$ flow-rate $(1-4 \mathrm{ml} / \mathrm{min})$, static extraction time (0-10 $\mathrm{min})$, and dynamic extraction time (0-30 min) in order to study their effects on the extraction. In addition, effects of sample mass $(0.2$ and $0.5 \mathrm{~g}$ ), 4-NP content ( 45 and $90 \mathrm{mg} / \mathrm{kg}$ ), water content and modifier methanol were also investigated. After depressurization of the supercritical fluid, the extract was adsorbed on an octadecyl functionalized silica (ODS) gel trap, kept at $20^{\circ} \mathrm{C}$ when pure $\mathrm{CO}_{2}$ was used or at $68^{\circ} \mathrm{C}$ when methanol was used as modifier. The nozzle temperature was maintained at $20^{\circ} \mathrm{C}$ for pure $\mathrm{CO}_{2}$ and $15^{\circ} \mathrm{C}$ for methanol. At the end of the extraction, the nozzle and trap temperatures were maintained at 20 and $15^{\circ} \mathrm{C}$, respectively. The trap was rinsed with $0.5 \mathrm{ml}$ pentane and the final volume was adjusted to $1.0 \mathrm{ml}$.

\subsection{Soxhlet extraction}

The soil sample $(0.2$ or $0.5 \mathrm{~g})$ was extracted as follows. The soil sample was mixed with the same amount of $\mathrm{Na}_{2} \mathrm{SO}_{4}$ and extracted using $300 \mathrm{ml}$ pentane for $24 \mathrm{~h}$ at the rate of six cycles/s in a Soxhlet extraction apparatus. Extracts were loaded on a Snyder column and eluted with the pentane. The eluent was evaporated using a K-D (Kuderna-Danish) condensation apparatus. Finally, the extracts were concentrated to a volume of $2 \mathrm{ml}$ in a waterbath at $20^{\circ} \mathrm{C}$.

\subsection{Gas chromatographic analysis}

Extracts were analyzed using a GC system equipped with a MS detector (HP 1800A GCD, USA). Separation was performed using a $30 \mathrm{~m} \times 0.25$ mm I.D. HP-1 capillary column (J\&W Scientific, Folsom, CA, USA). Helium with a flow-rate 1.0 $\mathrm{ml} / \mathrm{min}$ was used as carrier gas. The GC oven program was as follows: injector temperature $250^{\circ} \mathrm{C}$, detector temperature $300^{\circ} \mathrm{C}$. Initial oven temperature was held at $70^{\circ} \mathrm{C}$ for $1 \mathrm{~min}$, then increased at a rate of $5^{\circ} \mathrm{C} / \mathrm{min}$ to $180^{\circ} \mathrm{C}$, held for $3 \mathrm{~min}$, then increased at a rate of $10^{\circ} \mathrm{C} / \mathrm{min}$ to $280^{\circ} \mathrm{C}$, and was held for 5 min. The mass spectrometer was operated at $70 \mathrm{eV}$ and scanned from 30 to $425 \mathrm{u}$ at $1 \mathrm{scan} / \mathrm{s}$.

\subsection{Electron impact mass spectra of 4-NP}

The total ion current (TIC) profile of the standard of 4-NP (upper) was compared with the 4-NP in anaerobic sludge (lower) extracted by SFE. The figure revealed that 4-NP extracted from the sludge was the same as the standard 4-NP from Tokyo Chemicals. The details of the molecular ion peaks arising from the various isomers of 4-NP are clearly explained by Lee and Peart [7].

\section{Results and discussion}

The extraction parameters were optimized using 4-NP spiked samples. All the extractions were performed in triplicate under the fluid pressure 97 bar, temperature $40^{\circ} \mathrm{C}$, flow-rate $3.0 \mathrm{ml} / \mathrm{min}$, static extraction time $2 \mathrm{~min}$, dynamic extraction time 5 min, and modifier methanol $(0.5 \mathrm{ml})$. Higher recovery was obtained under the above optimal conditions. Analysis of the samples collected from different sewage/waste water treatment plants in Taiwan by SFE and Soxhlet method showed that 4-NP is present only in the anaerobic sludge of De-Haw STP. The efficiency of SFE was compared with the conventional Soxhlet extraction method using the spiked 4-NP samples. It is also noted the recovery of 4-NP is much higher when compared to the recovery of other organic pollutants by other research groups $[6,9,10]$.

\subsection{Effect of pressure on the extraction of 4-NP}

Fluid pressure is the main parameter that influences the recovery of organic compounds. Recent studies reveals that a maximum fluid density can be obtained at high pressures at a given temperature, which can enhance the strength of the solvent. Reidel and Höffler [6] optimized the extraction pressure during the SFE of polycyclic aromatic hydrocarbons 
(PAHs) from soil samples. In their study, the recovery of PAHs increased with increase of pressure from 8.5 to $40 \mathrm{MPa}$ but a slight decrease in the recovery was observed when the pressure was increased to $60 \mathrm{MPa}$ [6]. A similar trend was observed in the present study. When the fluid pressure was increased from 77 to 97 bar, the recovery of 4-NP dramatically increased from 56 to $98 \%$ and the fluid density also increased from 0.25 to $0.60 \mathrm{~g} / \mathrm{ml}$. The other extraction parameters such as fluid temperature, $\mathrm{CO}_{2}$ flow-rate, static extraction time and dynamic extraction time were controlled at $40^{\circ} \mathrm{C}, 2.0$ $\mathrm{ml} / \mathrm{min}, 2 \mathrm{~min}$ and $5 \mathrm{~min}$, respectively. When the pressure was increased from 97 to 164 bar, the recovery of 4-NP decreased to $84 \%$. With increasing density, the solvating power of the extraction solvent is increased which is responsible for the higher recoveries but at higher densities the diffusion coefficients are decreased. The decrease in the diffusion coefficients can cause lower recoveries at higher pressures due the kinetics of the extraction process [6]. Therefore, 97 bar was considered as the optimal fluid pressure for the extraction and under these conditions, the relative standard deviation (RSD) was $0.63 \%$.

\subsection{Effect of temperature on the extraction of 4-NP}

The recovery of 4-NP from the spiked quartz sand decreased from 97 to $79 \%$ when the fluid temperature increased from 40 to $60^{\circ} \mathrm{C}$. The fluid pressure, $\mathrm{CO}_{2}$ flow-rate, static extraction time and dynamic extraction time were controlled at $97 \mathrm{bar}, 2.0 \mathrm{ml} /$ $\min , 2 \mathrm{~min}$ and $5 \mathrm{~min}$, respectively. When Lee and Peart increased the temperature from 80 to $100^{\circ} \mathrm{C}$ during the supercritical fluid extraction of 4-NP, they have also observed the decrease in the recovery [7]. At constant pressure, the density of fluid decreases with increase of temperature. It was observed that there was a decrease in the fluid density from 0.60 to $0.27 \mathrm{~g} / \mathrm{cm}^{3}$ and the decrease in the recovery was due to the decrease in the density. However, the recovery of 4-NP increased from 79 to $90 \%$, when temperature was increased from 60 to $100^{\circ} \mathrm{C}$. It is due to the increase in the solvating power of the solvent with increasing temperature. Based on the above results, the optimal temperature was taken as $40^{\circ} \mathrm{C}$.

\subsection{Effect of static extraction time on the extraction of 4-NP}

SFE can be done in static, dynamic or combination modes. In most instances a combination mode, in which a short period of time is allowed for static extraction before dynamic extraction is performed. In this study the extractions were performed in a combination mode. The fluid pressure, temperature, flow-rate and dynamic extraction were controlled at $97 \mathrm{bar}, 40^{\circ} \mathrm{C}, 2.0 \mathrm{ml} / \mathrm{min}$ and $5 \mathrm{~min}$, respectively. Increasing static extraction time from 0 to $2 \mathrm{~min}$, an increase in the 4-NP recovery from 91 to $98 \%$ was observed. In addition, the RSD value decreased from 6.8 to $0.6 \%$. However, for longer static extraction time, the 4-NP recovery was found to be low. When static extraction time was increased from 2 to 10 min, the recovery of 4-NP decreased from 98 to $72 \%$. This result reveals that the optimal static extraction time was established as $2 \mathrm{~min}$.

\subsection{Effect of $\mathrm{CO}_{2}$ flow-rate on the extraction of 4-NP}

Once quantitative collection conditions have been developed for the analytes of interest, the effects experimental parameters which is responsible for sweeping the analytes out of thimble has to be evaluated. The effect of fluid flow-rate can either be negligible, or very important depending on the process that controls the overall rate of extraction of a particular sample. Table 1 summarizes the effect of flow-rate on the 4-NP recovery and RSD during SFE of spiked quartz sand. It is evident from Fig. 1 that the extraction was not influenced by the flow-rate of supercritical $\mathrm{CO}_{2}$. Lee and Peart, during the extraction of 4-NP have also observed a similar effect of flow-rate [7]. In the present study, the optimal fluid flow-rate was considered as $3 \mathrm{ml} / \mathrm{min}$ because the total consumption of supercritical $\mathrm{CO}_{2}$ was $15 \mathrm{ml}$ for the $3 \mathrm{ml} / \mathrm{min}$ flow-rates whereas the total consumption of supercritical $\mathrm{CO}_{2}$ was $20 \mathrm{ml}$ for both the 2 and $4 \mathrm{ml} / \mathrm{min}$ flow-rates.

\subsection{Effect of sample mass and 4-NP content on the extraction}

Fig. 2 reveals the effect of sample mass and 4-NP 
Table 1

Effect of flow-rate on the 4-NP recovery and RSD during SFE of spiked quartz sand ${ }^{\mathrm{a}}$

\begin{tabular}{|c|c|c|c|c|c|c|c|c|}
\hline \multirow{3}{*}{$\begin{array}{l}\text { Dynamic } \\
\text { extraction } \\
\text { time (min) }\end{array}$} & \multicolumn{8}{|c|}{ Flow-rate $(\mathrm{ml} / \mathrm{min})$} \\
\hline & \multicolumn{2}{|l|}{1.0} & \multicolumn{2}{|l|}{2.0} & \multicolumn{2}{|l|}{3.0} & \multicolumn{2}{|l|}{4.0} \\
\hline & $\begin{array}{l}\text { Recovery } \\
(\%)\end{array}$ & $\begin{array}{l}\text { RSD } \\
(\%)\end{array}$ & $\begin{array}{l}\text { Recovery } \\
(\%)\end{array}$ & $\begin{array}{l}\text { RSD } \\
(\%)\end{array}$ & $\begin{array}{l}\text { Recovery } \\
(\%)\end{array}$ & $\begin{array}{l}\text { RSD } \\
(\%)\end{array}$ & $\begin{array}{l}\text { Recovery } \\
(\%)\end{array}$ & $\begin{array}{l}\text { RSD } \\
(\%)\end{array}$ \\
\hline 0 & 0 & 0 & 0 & 0 & 0 & 0 & 0 & 0 \\
\hline 1 & 28.3 & 16.5 & 49.1 & 6.2 & 52.8 & 4.0 & 54.1 & 7.0 \\
\hline 2 & 70.0 & 8.4 & 87.7 & 5.5 & 90.5 & 3.7 & 91.9 & 4.3 \\
\hline 5 & 80.0 & 4.8 & 98.1 & 0.6 & 100.8 & 1.8 & 101.1 & 2.5 \\
\hline 10 & 91.4 & 3.0 & 101.2 & 4.0 & 101.4 & 6.4 & 103.2 & 3.3 \\
\hline 20 & 101.7 & 3.7 & 101.8 & 4.0 & 101.8 & 3.5 & 103.4 & 2.0 \\
\hline 30 & 99.7 & 3.9 & 101.8 & 1.7 & 102.4 & 2.0 & 101.7 & 3.5 \\
\hline
\end{tabular}

${ }^{\mathrm{a}}$ Variation with dynamic extraction time. Controlled extraction parameters: sample mass $0.5 \mathrm{~g}$, pressure 97 bar, temperature $40^{\circ} \mathrm{C}$, static extraction time $2 \mathrm{~min}$.

content on the recovery of 4-NP spiked Hsin-Chu anaerobic sludge. The effects of the above two parameters on the recovery of 4-NP were insignificant. The recovery of $4-\mathrm{NP}$ was $100 \%$ after controlling the dynamic extraction time to $5 \mathrm{~min}$. Field et al. have shown that the effect of sample mass during extraction of sulfonated aliphatic and aromatic surfactants from the sewage sludge by SFE was insignificant [11]. In this study, when $0.2 \mathrm{~g}$ sample was extracted, recovery was $1.04 \mathrm{~g} / \mathrm{min}$. For a 0.5 -g sample, the recovery was $0.42 \mathrm{~g} / \mathrm{min}$. Comparison of the recoveries showed that optimal sample mass was $0.2 \mathrm{~g}$. While studying the effect of 4-NP content on the extraction, the rate of recovery for both 45 and $90 \mathrm{mg} / \mathrm{kg}$ of $4-\mathrm{NP}$ was 0.21 . No significant effect was observed. Wuchner et al. used two spiking levels (4 and $40 \mathrm{ppm}$ ) to evaluate the effect of pesticides content on the recovery [12]. The results show that typically $90-95 \%$ recoveries were obtained for both spiking levels, suggesting that SFE is applicable over a wide range of concentrations. The effect of sample mass and analyte content on the 4-NP recovery and RSD during SFE of Hsin-Chu anaerobic sludge is presented in Table 2 .

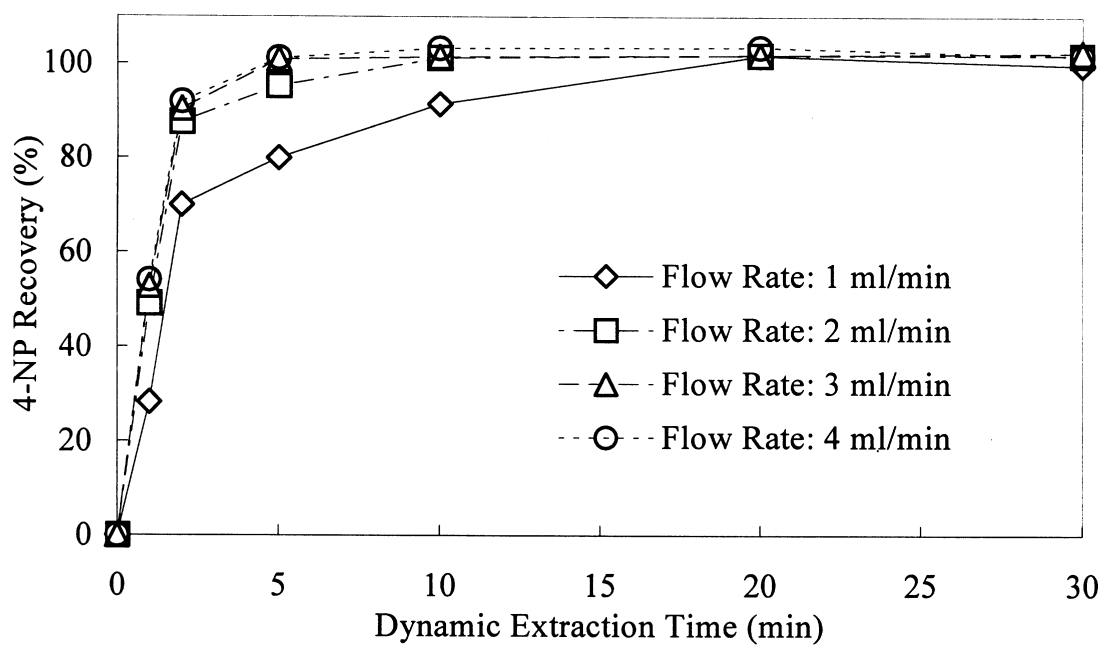

Fig. 1. Effect of $\mathrm{CO}_{2}$ flow-rate on the 4-NP recovery and RSD during SFE of spiked quartz sand. Variation with dynamic extraction time. Conditions: sample mass $0.5 \mathrm{~g}$, pressure $97 \mathrm{bar}$, temperature $40^{\circ} \mathrm{C}$, and static extraction time $2 \mathrm{~min}$. 


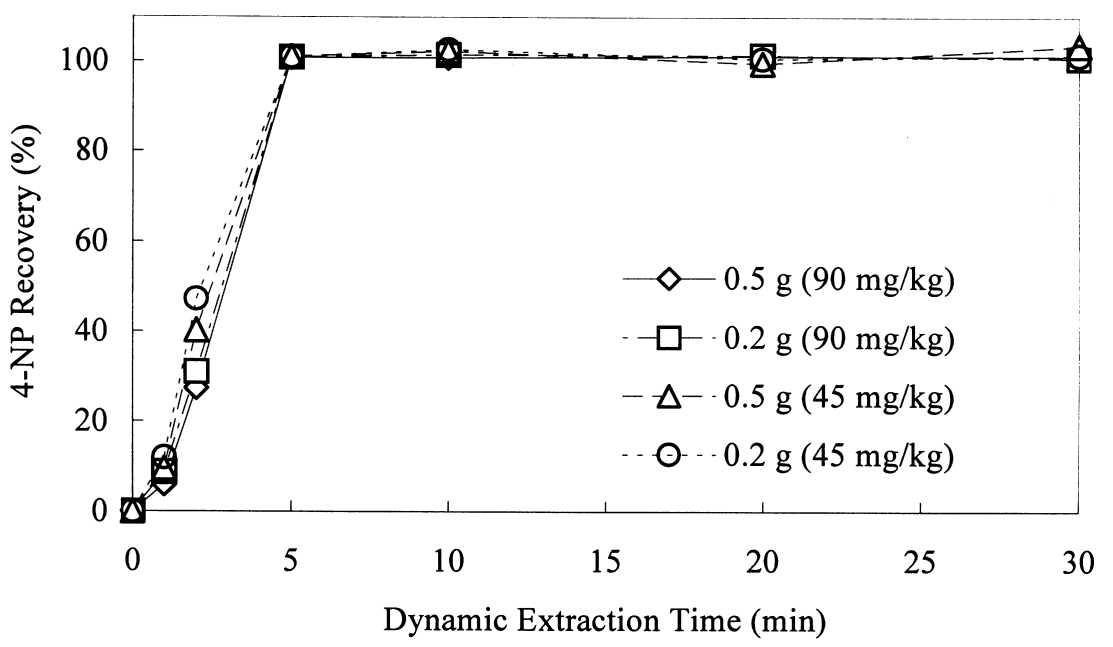

Fig. 2. Effect of sample mass and analyte content on the 4-NP recovery and RSD during SFE of Hsin-Chu anaerobic sludge. Variation with dynamic extraction time. Conditons: pressure $97 \mathrm{bar}$, temperature $40^{\circ} \mathrm{C}, \mathrm{CO}_{2}$ flow-rate $3.0 \mathrm{ml} / \mathrm{min}$, and static extraction time $2 \mathrm{~min}$.

\subsection{Effect of modifier on the extraction of 4-NP}

Depending on the type of sample matrix and the analyte's retaining nature on the matrix the modifier may influence the extraction in three different ways: (1) increasing the analyte's solubility in the supercritical fluid as a result of analyte-modifier interactions in the fluid phase. (2) Facilitating the analyte desorption. The molecules of polar modifiers are able to interact with the matrix and compete efficiently with the analytes for the active sites in the matrix. (3) Distorting the matrix. Analyte diffusion and penetration of the supercritical fluid inside the matrix are favored when the modifier swells the matrix. This phenomenon was found to be an important factor in modifier-enhanced SFE $[5,10,13]$.

Fig. 3A illustrates the effect of water content and methanol on the recovery of 4-NP spiked Hsin-Chu anaerobic sludge. The sludge was dried using $\mathrm{Na}_{2} \mathrm{SO}_{4}$ and the water content was $0 \%$, the recovery of 4-NP observed was $61 \%$ after 30 min dynamic extraction. When the water content was increased to $8.8 \%$ the recovery of 4 -NP was $100 \%$ after 5 min dynamic extraction. This happened due to the presence of water, which can also act as a modifier. Water and 4-NP can interact with each other through

Table 2

Effect of sample mass and analyte content on the 4-NP recovery and RSD during SFE of Hsin-Chu anaerobic sludge ${ }^{\mathrm{a}}$

\begin{tabular}{|c|c|c|c|c|c|c|c|c|}
\hline \multirow{3}{*}{$\begin{array}{l}\text { Dynamic } \\
\text { extraction } \\
\text { time (min) }\end{array}$} & \multicolumn{4}{|c|}{ Sample mass $0.5 \mathrm{~g}$} & \multicolumn{4}{|c|}{ Sample mass $0.2 \mathrm{~g}$} \\
\hline & \multicolumn{2}{|l|}{$90 \mathrm{mg} / \mathrm{kg}$} & \multicolumn{2}{|l|}{$45 \mathrm{mg} / \mathrm{kg}$} & \multicolumn{2}{|l|}{$90 \mathrm{mg} / \mathrm{kg}$} & \multicolumn{2}{|l|}{$45 \mathrm{mg} / \mathrm{kg}$} \\
\hline & $\begin{array}{l}\text { Recovery } \\
(\%)\end{array}$ & $\begin{array}{l}\text { RSD } \\
(\%)\end{array}$ & $\begin{array}{l}\text { Recovery } \\
(\%)\end{array}$ & $\begin{array}{l}\text { RSD } \\
(\%)\end{array}$ & $\begin{array}{l}\text { Recovery } \\
(\%)\end{array}$ & $\begin{array}{l}\text { RSD } \\
(\%)\end{array}$ & $\begin{array}{l}\text { Recovery } \\
(\%)\end{array}$ & $\begin{array}{l}\text { RSD } \\
(\%)\end{array}$ \\
\hline 0 & 0 & 0 & 0 & 0 & 0 & 0 & 0 & 0 \\
\hline 1 & 6.0 & 19.4 & 9.6 & 8.8 & 8.8 & 30.1 & 11.9 & 7.6 \\
\hline 2 & 27.4 & 12.0 & 40.3 & 3.4 & 31.1 & 8.9 & 47.2 & 3.1 \\
\hline 5 & 100.8 & 3.5 & 101.2 & 1.2 & 101.0 & 2.2 & 101.1 & 1.1 \\
\hline 10 & 100.8 & 1.6 & 102.3 & 2.0 & 101.5 & 1.3 & 102.7 & 0.8 \\
\hline 20 & 101.2 & 0.6 & 99.6 & 1.5 & 101.5 & 0.7 & 100.6 & 1.0 \\
\hline 30 & 101.2 & 1.8 & 103.5 & 0.9 & 100.8 & 1.2 & 101.3 & 0.6 \\
\hline
\end{tabular}

\footnotetext{
${ }^{a}$ Variation with dynamic extraction time. Controlled extraction parameters: pressure $97 \mathrm{bar}$, temperature $40^{\circ} \mathrm{C}$, flow-rate $3.0 \mathrm{ml} / \mathrm{min}$,
} static extraction time $2 \mathrm{~min}$. 

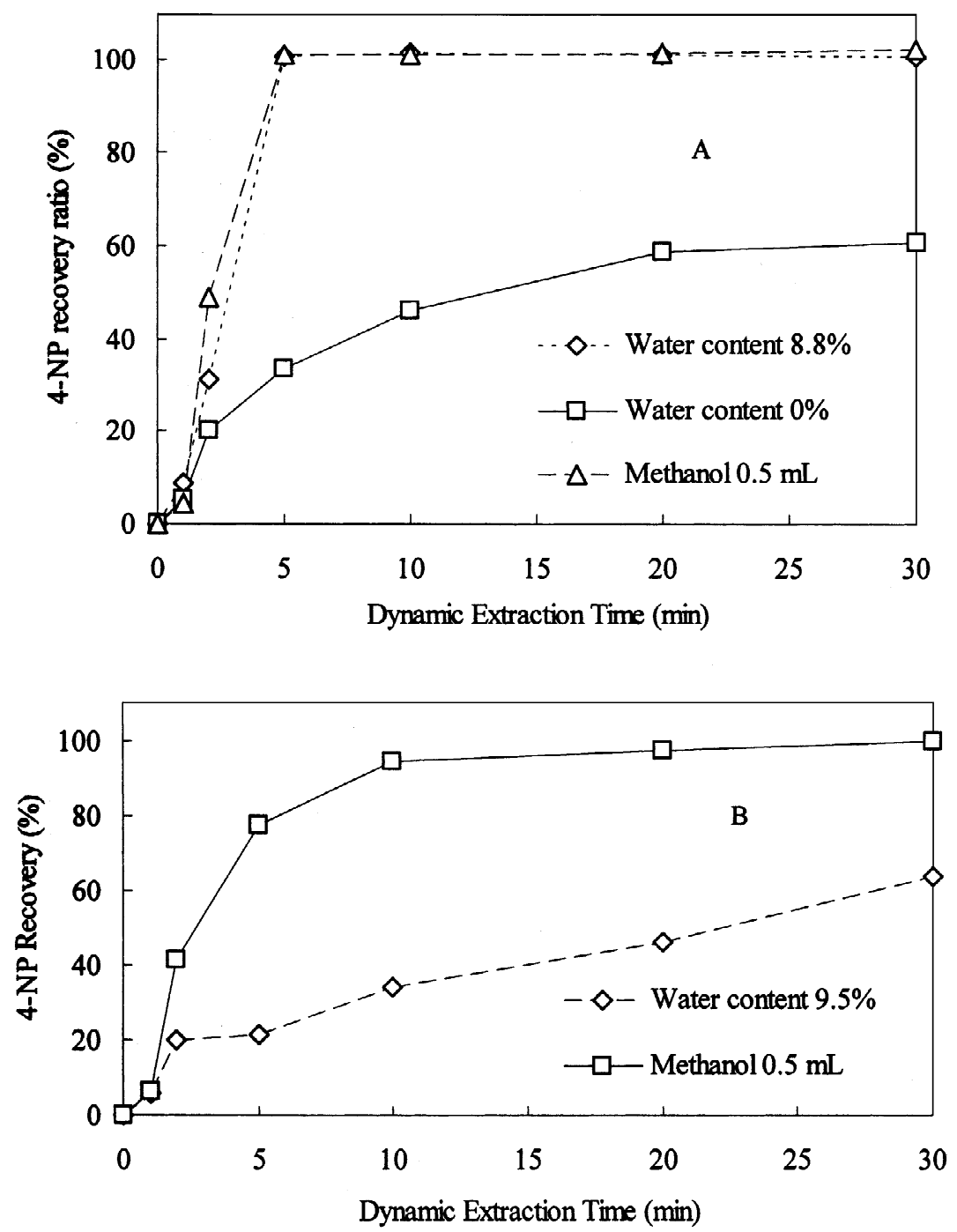

Fig. 3. Effect of water content and modifier on the 4-NP recovery and RSD during SFE of spiked Hsin-Chu anaerobic sludge (A) and De-Haw anaerobic sludge (B). Variation with dynamic extraction time. Conditions: sample mass $0.2 \mathrm{~g}$, pressure 97 bar, temperature $40^{\circ} \mathrm{C}$, $\mathrm{CO}_{2}$ flow-rate $3.0 \mathrm{ml} / \mathrm{min}$, and static extraction time $2 \mathrm{~min}$.

hydrogen bonding. In this work, we also used methanol as a modifier to evaluate its effect on the recovery of 4-NP. Fig. $3 \mathrm{~A}$ shows that methanol $(0.5$ $\mathrm{ml}$ ) could increase the recovery of 4-NP and it was $100 \%$ for 5 min dynamic extraction. The mechanism of the reaction with methanol as a modifier is same as that of water, which interacts with the analyte through hydrogen bonding.

In addition, the recovery of 4-NP in the sludge was only $64 \%$ with $9.5 \%$ water content after $30 \mathrm{~min}$ dynamic extraction (Fig. 3B). But the recovery of
4-NP was $100 \%$ after 30 min dynamic extraction when it was with the modifier methanol $(0.5 \mathrm{ml})$. The total concentration of 4-NP extracted by SFE from the anaerobic sludge of De-Haw STP was $243.9 \mathrm{mg} / \mathrm{kg}$ and the RSD value was $0.9 \%$. The concentration of 4-NP in anaerobic sludge of DeHaw STP extracted by Soxhlet extraction method was $227.0 \mathrm{mg} / \mathrm{kg}$ and the RSD value was $2.6 \%$. It is evident from the above results that better recovery and high precision were obtained using SFE and hence SFE technique can be applied efficiently for 
Table 3

Effect of water content and methanol on the 4-NP recovery and RSD during SFE of Hsin-Chu anaerobic sludge ${ }^{\mathrm{a}}$

\begin{tabular}{|c|c|c|c|c|c|c|}
\hline \multirow{3}{*}{$\begin{array}{l}\text { Dynamic extraction } \\
\text { time (min) }\end{array}$} & \multicolumn{4}{|l|}{ Water content } & \multicolumn{2}{|c|}{ Methanol, $5.0 \mathrm{ml}$} \\
\hline & \multicolumn{2}{|l|}{$0 \%$} & \multicolumn{2}{|l|}{$8.8 \%$} & \multirow[t]{2}{*}{ Recovery (\%) } & \multirow[t]{2}{*}{$\operatorname{RSD}(\%)$} \\
\hline & Recovery (\%) & $\operatorname{RSD}(\%)$ & Recovery (\%) & RSD $(\%)$ & & \\
\hline 0 & 0 & 0 & 0 & 0 & 0 & 0 \\
\hline 1 & 5.1 & 24.9 & 8.8 & 30.1 & 4.3 & 33.3 \\
\hline 2 & 20.2 & 13.7 & 31.1 & 8.9 & 48.8 & 5.8 \\
\hline 5 & 33.6 & 12.8 & 101.0 & 2.3 & 101.2 & 1.4 \\
\hline 10 & 46.1 & 8.2 & 101.5 & 1.3 & 101.2 & 2.5 \\
\hline 20 & 58.6 & 5.3 & 101.5 & 0.7 & 101.9 & 1.4 \\
\hline 30 & 60.9 & 7.6 & 100.8 & 1.2 & 102.4 & 1.7 \\
\hline
\end{tabular}

${ }^{a}$ Variation with dynamic extraction time. Controlled extraction parameters: sample mass $0.2 \mathrm{~g}$, pressure 97 bar, temperature $40^{\circ} \mathrm{C}$, flow-rate $3.0 \mathrm{ml} / \mathrm{min}$, static extraction time $2 \mathrm{~min}$.

the determination of 4-NP and other organic compounds. The effect of water content and methanol on the 4-NP recovery and RSD during SFE of Hsin-Chu anaerobic sludge and De-Haw anaerobic sludge are presented in Tables 3 and 4, respectively.

\subsection{Recovery of 4-NP from the sludge of STP}

Determination of recovery of the spiked analytes from environmental samples is a routine procedure for developing new extraction techniques. In this work, the optimal condition for the extraction of the spiked sample was: fluid pressure 97 bar, temperature $40^{\circ} \mathrm{C}$, flow-rate $3.0 \mathrm{ml} / \mathrm{min}$, static extraction time $2 \mathrm{~min}$, dynamic extraction time $5 \mathrm{~min}$, and modifier methanol $(0.5 \mathrm{ml})$. When the above optimal condition was applied for the anaerobic sludge of De-Haw STP, the recovery of 4-NP from the sludge was only $77 \%$. Spiked analytes on real-world samples may not be situated on the same binding sites as that of the native analytes because of kinetic and diffusional limitations of the sorption process and several possible interactions may exist simultaneously between a particular analyte and a complex matrix. Table 5 shows the presence of 4-NP in different sewage treatment plants.

\section{Conclusions}

The present study demonstrates the efficiency of SFE for the quantitative removal of 4-NP from the anaerobically biodegraded sewage sludge under optimal conditions. Raising the extraction pressure from 77-97 bar greatly increases the recovery because of the increase in the fluid density. Further increase in

Table 4

Effect of water content and methanol on the 4-NP concentration and RSD during SFE of De-Haw anaerobic sludge ${ }^{a}$

\begin{tabular}{|c|c|c|c|c|}
\hline \multirow{2}{*}{$\begin{array}{l}\text { Dynamic extraction } \\
\text { time (min) }\end{array}$} & \multicolumn{2}{|l|}{ Water content, $9.5 \%$} & \multicolumn{2}{|l|}{ Methanol, $0.5 \mathrm{ml}$} \\
\hline & Concentration $(\mathrm{mg} / \mathrm{kg})$ & $\operatorname{RSD}(\%)$ & Concentration $(\mathrm{mg} / \mathrm{kg})$ & $\operatorname{RSD}(\%)$ \\
\hline 0 & 0 & 0 & 0 & 0 \\
\hline 1 & 14.4 & 5.3 & 15.9 & 4.1 \\
\hline 2 & 48.2 & 1.4 & 100.3 & 0.4 \\
\hline 5 & 52.7 & 4.3 & 188.7 & 0.3 \\
\hline 10 & 83.4 & 2.9 & 229.9 & 0.4 \\
\hline 20 & 113.0 & 3.0 & 237.2 & 0.4 \\
\hline 30 & 155.7 & 1.2 & 243.9 & 0.9 \\
\hline
\end{tabular}

\footnotetext{
${ }^{\mathrm{a}}$ Variation with dynamic extraction time. Controlled extraction parameters: sample mass $0.2 \mathrm{~g}$, pressure 97 bar, temperature $40^{\circ} \mathrm{C}$,
} flow-rate $3.0 \mathrm{ml} / \mathrm{min}$, static extraction time $2 \mathrm{~min}$. 
Table 5

Concentration of 4-NP in different sewage treatment plants

\begin{tabular}{llll}
\hline Location & Sample type & [4-NP] $(\mathrm{mg} / \mathrm{kg} \pm$ SD) & $n^{\mathrm{a}}$ \\
\hline Taipei (De-Haw) & STP sludge & $243.9 \pm 2.1$ & 3 \\
Toronto (Leslie) $^{\mathrm{c}}$ & STP sludge & $470 \pm 22$ & 6 \\
Toronto (Highland Creek) $^{\mathrm{c}}$ & STP sludge & $137 \pm 7.7$ & 3 \\
England (STW1) $^{\mathrm{d}}$ & STP sludge & $326.0(255.6-414.6)$ & 3 \\
England (STW2) $^{\mathrm{d}}$ & STP sludge & $637.5(520.3-823.5)$ & 3 \\
\hline
\end{tabular}

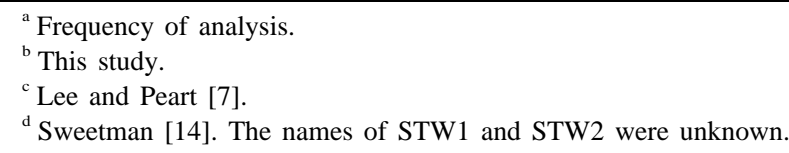

the pressure, decreases the recovery that is due to the decrease in the fluid diffusion coefficient. When the temperature was increased from $40-60^{\circ} \mathrm{C}$ there was a significant decrease in the recovery and when the temperature was further increased to $100^{\circ} \mathrm{C}$ the recovery is greater than $90 \%$. This could be explained by the fact that the increase in the recovery after a certain level of temperature is due to the increase in the fluid diffusion coefficient. It was also noted that longer extraction time resulted in a low recovery. This is attributed to the fact that under low-pressure conditions the binding energy between the organic compound and the matrix is less and hence better recovery could be obtained within a short extraction period [3]. Observation of recoveries at different flow-rates shows that the extraction was not influenced by the flow-rates. The results also illustrate that sample mass has an influence on the extraction but the 4-NP content has no effect on the extraction. The enhanced recovery in the presence of the modifier water and methanol is that they both can interact with the 4-NP through hydrogen bonding that would lead to a better recovery. Lower RSD value of supercritical fluid extraction concludes the accuracy and precision of this method is good. The occurrence of 4-NP in the sludge of different sewage treatment plants shows that before disposing of the sewage sludge into the environment a suitable cost effective, remediation process must be carried out.

\section{Acknowledgements}

The authors would like to thank the National Science Council, Republic of China, for their financial support (NSC 86-2211-E-009-007).

\section{References}

[1] W. Giger, P.H. Brunner, C. Schaffner, Science 225 (1984).

[2] B. Hileman, Chem. Eng. News, Jan. 31 (1994) 19.

[3] M.D. Burford, S.B. Hawthrone, D.J. Miller, Anal. Chem. 65 (1993) 1497.

[4] P. Chen, W. Zhou, L.L. Tavalarides, Environ. Prog. 16 (1997) 227.

[5] J.J. Langenfeld, S.B. Hawthrone, D.J. Miller, J. Pawliszyn, Anal. Chem. 65 (1993) 338.

[6] S. Reindl, F. Höfler, Anal. Chem. 66 (1994) 1808.

[7] H.B. Lee, T.E. Peart, Anal. Chem. 67 (1995) 1976.

[8] H.B. Lee, T.E. Peart, D.T. Bennie, R.J. Maguire, J. Chromatogr. A 785 (1997) 385.

[9] S.E. Eckert-Tilotta, S.B. Hawthorne, D.J. Miller, Fuel 72 (1993) 1015.

[10] S.B. Hawthorne, D.J. Miller, Anal. Chem. 66 (1994) 4005.

[11] J.A. Field, D.J. Miller, T.M. Field, S.B. Hawthorne, W. Giger, Anal. Chem. 64 (1992) 3161.

[12] K. Wuchner, R.T. Ghijsen, A.Th. Brinkman Udo, J. Mathieu, Analyst 118 (1993) 11.

[13] T.R. Steinheimer, R.L. Pfeiffer, K.D. Scoggin, Anal. Chem. 66 (1994) 645.

[14] A.J. Sweetman, Water Res. 28 (1994) 343. 